Prentice, C.R.M. \& Davidson, J.F. (1973) Drug-induced activation of fibrinolysis. Clinics in Haematology, 2, 159.

Schaffner, F., Popper, H. \& Chesrow, E. (1959) Cholestasis produced by the administration of norethandrolone. American Journal of Medicine, 26, 249.

Schaffner, F., Popper, H. \& Perez, V. (1960) Changes in bile canaliculi produced by norethandrolone: electron microscopic study of human and rat liver. Journal of̊ Laboratory and Clinical Medicine, 56, 623.

SHERLOCK, S. (1968) Diseases of the Liver and Biliary System 4th edn., p. 371. Blackwell Scientific Publications: Oxford. WERner, S.C., HANGer, F.M. \& Kritzler, R.A. (1950) Jaundice during methyl testosterone therapy. American Journal of Medicine, 8, 325.

\title{
Gout induced by L-dopa and decarboxylase inhibitors
}

\author{
D. B. CALNE * \\ M.D. \\ J. Fermaglich \\ M.D.
}

\begin{abstract}
National Institute of Neurological and Communicative Disorders and Stroke, National Institutes of Health, Department of Health, Education and Welfare, Bethesda, Maryland, and Department of Neurology, Georgetown University Hospital, Washington, D.C., U.S.A.
\end{abstract}

\begin{abstract}
Summary
Two cases of clinical gout are reported in parkinsonian patients receiving $\mathrm{L}$-dopa in combination with a decarboxylase inhibitor. Blockade of decarboxylation leads to major changes in the pattern of L-dopa metabolites. It is suggested that hyperuricaemia may result from accumulation of $L$-dopa itself or a transaminated product.
\end{abstract}

\section{Introduction}

HoNDA and Gindin (1972) have reported two patients who developed the clinical and biochemical features of gout while receiving L-dopa for parkinsonism. Elevation of the serum uric acid may occur more commonly without arthropathy though misleading measurements can result from L-dopa interfering with non-specific assay techniques (Cawein and Hewins, 1969). The mechanism by which L-dopa induces gout is not known. Two patients have recently been encountered who developed gout while taking L-dopa in combination with a decarboxylase inhibitor; one was receiving carbidopa and the other $\alpha$-methyldopa.

\section{Case reports}

Case no. 1, aged 52 years, first noticed tremor in his left hand 10 years ago. This spread to involve the left leg and idiopathic parkinsonism was diagnosed. In 1968 he underwent stereotactic thalamotomy. His tremor improved but his speech and gait deteriorated. There was no family history of parkinsonism or gout

* Address: Building 10, Room 6D20, National Institutes of Health, Bethesda, Maryland 20014, U.S.A. and no previous encephalitis or exposure to neuro- $\rightarrow$ toxic materials. He developed mild tremor on the right. Cogwheeling was present at both wrists and his tendon reflexes were brisk on the left. He wass initially treated with benzhexol $(4 \mathrm{mg} /$ day) and then. L-dopa ( $5.5 \mathrm{~g} /$ day). In March 1973 he started taki carbidopa $100 \mathrm{mg} / \mathrm{day}$, the dose of L-dopa being reduced to $2.5 \mathrm{~g} /$ day because of dyskinesia.

Three months after starting carbidopa he developed

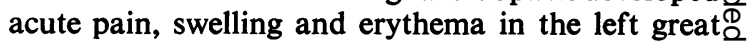
toe. This resolved spontaneously over a week. After $\overrightarrow{\vec{\circ}}$ a week free of pain his symptoms returned. His serum 3 uric acid was found to be $6.9 \mathrm{mg} / 100 \mathrm{ml}$. Gout was? diagnosed and he was given allopurinol $300 \mathrm{mg} /$ day. A week later the dose was reduced to $200 \mathrm{mg}$ /day and pain returned in his left great toe. He returned to 3 . $300 \mathrm{mg} /$ day and has been free of pain since. The dosage of carbidopa and L-dopa has not been. changed. His serum uric acid in January 1974 was $ᄋ$ $4 \cdot 2 \mathrm{mg} / 100 \mathrm{ml}$. Allopurinol was stopped for 1 week in order to estimate his urinary output of uric acid, 음 which was found to be $0.98 \mathrm{~g}$ over $24 \mathrm{hr}$ (normal up to $0.4 \mathrm{~g}$ ).

Case no. 2, aged 75 years, offered a 20-year history of parkinsonism. His initial symptoms were tremor ${ }^{\circ}$ of both lower extremities which progressed slowly. $N$ $\mathrm{He}$ also experienced bradykinesia manifested by difficulty in arising from the sitting and supine? positions. His gait displayed slowness, shuffling, 0 festination, and propulsion. His balance was im- $\frac{\Phi}{D}$ paired. Speech was of low tone and poor quality. $\stackrel{\odot}{+}$ Sialorrhoea and dysphagia were present. There was 0 no family history of gout. Previous routine blood $\stackrel{\vec{D}}{\vec{D}}$ tests had shown normal concentrations of uric acid. 
For several years he had been treated with procyclidine, $5 \mathrm{mg}$ three times daily. In October 1970 he was started on L-dopa and $\alpha$-methyldopa. The dose of the former agent was increased to a daily intake of 2.25 $\mathrm{g}$, and the latter to a maintenance level of $0.75 \mathrm{~g} /$ day.

Two years after starting L-dopa and $\alpha$-methyldopa the patient developed severe pain in both knees. The serum uric acid was $9.2 \mathrm{mg} / 100 \mathrm{ml}$. Allopurinol was prescribed, $100 \mathrm{mg}$ twice daily, and his arthralgia improved. The serum uric acid fell to $8.4 \mathrm{mg} / 100 \mathrm{ml}$ and then to $5.8 \mathrm{mg} / 100 \mathrm{ml}$; allopurinol was continued at the same dose for 6 months. Three months following the termination of allopurinol, the uric acid concentration was $7.7 \mathrm{mg} / 100 \mathrm{ml}$. He remained free of joint pain on $2.5 \mathrm{~g}$ /day of L-dopa and 0.75 $\mathrm{g} /$ day of $\alpha$-methyldopa for 7 months, when joint pains recurred. Serum uric acid was $8.7 \mathrm{mg} / 100 \mathrm{ml}$, and allopurinol $100 \mathrm{mg}$ twice daily was restarted. He continues on this regimen.

\section{Discussion}

It is concluded that decarboxylated metabolites of L-dopa, such as the catecholamines, are unlikely to be involved in producing the disturbances of uric acid metabolism seen in patients receiving L-dopa. L-dopa, or the products of 3-O-methylation and transamination may be responsible.

There is no evidence that the decarboxylase inhibitors, carbidopa or $\alpha$-methyldopa, induce gout by themselves, so it is probable that their administration together with L-dopa leads to accumulation of a product causing hyperuricaemia. L-dopa itself is one possible candidate for this role. Comparison of plasma levels of $\mathrm{L}$-dopa in patients on maximum tolerated dosage with and without a decarboxylase inhibitor indicates that while peak plasma concentrations are similar, blockade of decarboxylation leads to more sustained levels of L-dopa (Reid et al., 1972); the areas under the plasma concentration curves, representing the quantity of levodopa in the blood, are increased.

There have been a number of studies involving administration of high doses of 3-O-methyldopa (3OMD) to parkinsonian patients (Gauthier et al., 1971; Muenter, Sharpless and Tyce, 1972; Calne, Reid and Vakil, 1973) but abnormalities of serum uric acid have not been reported in these investi- gations. Beeause of the more limited experience with 3OMD comparcd with that of L-dopa, these negative findings cannot be regarded as firm evidence against incriminating a 3-O-methylated metabolite in gout.

If L-dopa is not itself responsible for the development of gout, the most likely metabolite to be involved is a transamination product. Analysis of the urine of patients receiving L-dopa with and without decarboxylase inhibition has shown that a major shift towards transamination is induced by blocking decarboxylation (Sandler et al., 1974). The shunting of L-dopa down transamination pathways could lead to accumulation of a toxic product responsible for hyperuricaemia.

Further studies are desirable to obtain evidence on whether L-dopa itself or a transaminated metabolite is responsible. As L-dopa and its metabolites are physiological substances, such investigations may even contribute to the elucidation of the metabolic disturbances underlying spontaneous gout.

\section{Acknowledgment}

This study was supported in part by a generous grant from the American Parkinson's Disease Association, New York, New York, U.S.A.

\section{References}

Calne, D.B., ReID, J.L. \& VAKIL, S.D. (1973) Parkinsonism treated with 3-O-methyldopa. Clinical Pharmacology and Therapeutics, 14, 386.

Cawein, M.J. \& Hewins, J. (1969) False rise in serum uric acid after L-dopa. New England Journal of Medicine, 281, 1489.

Gauthier, G., de Auuriaguerra, J., Geissbuhler, F., Simona, B., Constantinidis, J., Yanniotis, G., Krassoievitch, M., EisnRing, J.J. \& Tissot, R. (1971) Thérapeutique substitutive des syndromes de parkinson. Presse Médicale, 79, 91.

HoNDA, H. \& Gindin, R.A. (1972) Gout while receiving levodopa for parkinsonism. Journal of the American Medical Association, 219, 55.

Muenter, M.D., Sharpless, N.S. \& Tyce, G.M. (1972) Plasma 3-O-methyldopa in L-dopa therapy of Parkinson's disease. Mayo Clinic Proceedings, 47, 389.

Reid, J.L., Calne, D.B., Vakil, S.D., Allen, J.G. \& Davies, C. (1972) Plasma concentration of levodopa in parkinsonism before and after inhibition of peripheral decarboxylase. Journal of the Neurological Sciences, 17, 45.

SAndler, M., Johnson, R.D., RuthVen, C.R.J., ReID, J.L. \& CALNE, D.B. (1974) Transamination is a major pathway of L-dopa metabolism following peripheral decarboxylase inhibition. Nature. London, 247, 364. 